\title{
BMJ Open Provider and service-user perspectives of volunteer health-worker service provision in Ayeyarwady Region, Myanmar: a qualitative study
}

\author{
Nicola Watt, ${ }^{1}$ Aye Yupar, ${ }^{2,3}$ Paul Sender, ${ }^{2,3}$ Fiona Campbell, ${ }^{1,2}$ \\ Helena Legido-Quigley, ${ }^{4}$ Natasha Howard ${ }^{1}$
}

To cite: Watt N, Yupar A, Sender $\mathrm{P}$, et al. Provider and service-user perspectives of volunteer health-worker service provision in Ayeyarwady Region, Myanmar: a qualitative study. BMJ Open 2016;6:e012762. doi:10.1136/bmjopen-2016012762

- Prepublication history and additional material is available. To view please visit the journal (http://dx.doi.org/ 10.1136/bmjopen-2016012762).

Received 14 June 2016 Revised 29 September 2016 Accepted 3 October 2016

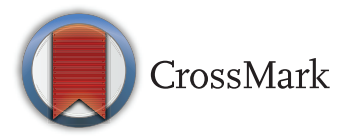

${ }^{1}$ Faculty of Public Health and Policy, London School of Hygiene \& Tropical Medicine, London, UK

${ }^{2}$ Formerly Merlin Country Office, Yangon, Myanmar ${ }^{3}$ PR-GFATM, UNOPS,

Yangon, Myanmar

${ }^{4}$ Saw Swee Hock School of

Public Health, National

University of Singapore,

Singapore, Singapore

Correspondence to Dr Nicola Watt;

Nicola.watt@gmx.com

\section{ABSTRACT}

Objectives: To explore perspectives and reported experiences of service users, community providers and policymakers related to volunteer health-worker services provision in a rural area of Myanmar.

Methods: A qualitative interview study was conducted in rural communities with 54 service users and 17 community providers in Ayeyarwady Region, Myanmar, and with 14 national managers and policymakers in Yangon Myanmar. Topics included reasons for seeking health services, views and experiences, and comparison with experiences of other services. Data were analysed thematically using deductive and inductive coding.

Results: Accessibility and affordability were important to all participants. Service users described the particular relevance of trust, familiarity and acceptability in choosing a provider. Perceived quality and effectiveness were necessary for trust to develop. Perceived value of volunteers was a cross-cutting dimension, which was interpreted differently by different participants.

Conclusions: Results suggest that volunteers are appropriate and valued, and support 'availability', 'accessibility' and 'acceptability' as dimensions of health services access in this setting. However, social complexities should be considered to ensure effective service delivery. Further research into trust-building, developing quality perceptions and resulting serviceuser choices would be useful to inform effective policy and planning.

\section{BACKGROUND}

Globally, village health workers (VHWs) and similar community cadres were initially promoted for awareness-raising, preventive and curative community-based services, to help achieve the Alma Ata vision of 'Health for All'. With programmes falling short of high expectations, ${ }^{1}$ and changing macroeconomic and development policies, specific costeffective interventions overtook broad

\section{Strengths and limitations of this study}

- This is the first qualitative study to the best of our knowledge to explore a range of community and national perspectives on issues affecting access to community health services in Myanmar.

- Social acceptability bias may have affected some answers, though the number and range of participants helped counteract this.

- Research was not designed to identify relationships between demographic factors and decision-making.

- A mixture of deductive and inductive coding generated insights that require further discussion and research.

approaches. ${ }^{2-8}$ Reduced budgets helped revive interest in community cadres, volunteer and paid, and task-shifting. ${ }^{9}$ Debates

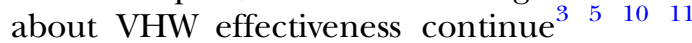
and there are recognised challenges in national scale-up of successful pilots. ${ }^{7} \quad 12$ However, evidence exists for promoting community cadres, when they are properly supported and integrated within primary healthcare systems. ${ }^{3-5}$ 13-17 WHO now includes community cadres in models to scale up a range of health services, ${ }^{15}{ }^{18}$ and the potential of community health workers (CHWs) has been flagged in the wake of the West Africa Ebola outbreak ${ }^{16}$ and as a key mechanism for achieving Sustainable Development Goals (SDGs). ${ }^{19}$

VHWs have a long history in Asia, with programmes in Thailand, Bangladesh and Pakistan often highlighted as successes. ${ }^{20}$ Myanmar adopted a primary healthcare approach, before the declaration of Alma Ata, focusing on maternal and child health, tuberculosis and malaria control, water and sanitation promotion. CHWs have been 
trained since the 1970s to support health education, assist in sanitation and immunisation, treat minor injuries and illnesses and coordinate with health facilities for early referral. CHWs are trained for at least 21 days under Ministry of Health and Sports (MoHS; formerly Ministry of Health) guidelines, augmented by a further 7 days in some programmes. Auxiliary midwives (AMWs) have been trained since the 1980s to provide antenatal care, safe home deliveries where midwives are unavailable, and assist midwives in maternal and child health and birth-spacing activities. AMWs are trained for 6 months, 3 under supervision of Basic Health Staff in a Rural Health Centre. Both cadres are recognised under MoHS policy and work as volunteers.

Positive political, economic and social changes are taking place in Myanmar. However, following decades of conflict and underinvestment in social services, the country ranks 150th (of 187 countries) in the UN Human Development Index and 24th in the Fund for Peace Fragile States Index. ${ }^{21}{ }^{22}$ The health system faces a range of challenges. Progress against global health targets is being made, ${ }^{23}$ though achievement of Millennium Development Goals 4 and 5 may not be feasible before $2020 .^{24}$ Historically, health expenditure in Myanmar was some of the lowest recorded globally. ${ }^{25}$ Internal and external funding have increased significantly since 2012, though government and external health funding remain low by international standards. ${ }^{26}$ Private out-of-pocket expenditures remain an access barrier. ${ }^{25}$ Approximately $70 \%$ of Myanmar's population of 51.4 million is rural ${ }^{25} 27$ and often in remote and hard-to-reach areas that challenge health services delivery.

At the time of the study, Myanmar's MoHS was organised at central, regional and township levels. ${ }^{28}{ }^{29}$ Township health departments oversee 1-3 station hospitals and 4-5 Rural Health Centres (RHCs). Each RHC supports 4-5 sub-RHCs (SRHCs) with a midwife supervising services in approximately seven villages (ie, 3000-4500 people) per SRHC. ${ }^{28-30}$ Historically, a significant avenue for external health support has been through community-based healthcare programmes. In 2014, MoHS announced an ambitious programme to scale up training of AMWs and CHWs nationally with the aim of providing one $\mathrm{CHW}$ and one AMW per village with no midwife or facility. ${ }^{31}$ While there is now increasing health system support at township level and above, community programmes remain an important aspect of the health system, including ensuring access to essential services for underserved populations. ${ }^{32}$

There is increasing global emphasis and Myanmar government commitment to universal health coverage and 'people-centred' health services. ${ }^{33}$ There is, however, no universally accepted model for planning communitybased services. ${ }^{13}{ }^{34}$ Thus, a literature review identified the number of volunteers per population served (ie, availability) and distance from a volunteer (ie, accessibility) as relevant, ${ }^{35}$ while Geographic Information
System (GIS) modelling by AY examined a theoretical scenario in which every village in a sample Myanmar township was within $2.5 \mathrm{~km}$ of a VHW, with a maximum of 1000 people per VHW. ${ }^{93} 38$ If applied, this would lead to a very different distribution, and significantly fewer $(50 \%)$ VHWs than supported at that point (see online supplementary figure S1a and b). However, this would be without regard for service-user views and preferences, for example, trust in particular providers. ${ }^{39-42}$

This study therefore aimed to explore factors affecting VHW (ie, AMW, CHW) service usage in Myanmar, by focusing on perspectives and reported experiences of service users, community providers and national policymakers related to volunteer health workers in a rural area of Myanmar. Results are relevant to practitioners establishing or implementing volunteer programmes and to broader policy debates on task-shifting.

\section{METHODS}

\section{Study design}

A qualitative study design was selected, incorporating in-depth interviews at community and national levels. The research question was 'How do service users experience accessing and receiving community-based healthcare?' The collective term VHW is used when referring to $\mathrm{CHW}$ and AMW cadres, as both are recognised under Myanmar policy.

\section{Study site}

An established international non-governmental organisation (INGO)-supported community health programme in Laputta Township, Ayeyarwady Division, with an average 1-2.5 CHWs and 0.3-1.3 AMWs per 1000 population, was chosen for community-level interviews due to its stability and availability of VHWs across the whole township. Twenty-six villages were selected to provide a range of sizes, remoteness, proximity to a health facility and age and sex of VHWs. Two that did not have VHWs were included to explore how choices were made in those villages. 'Hard-to-reach villages,' defined by travel time from an SRHC, were purposefully oversampled (ie, 4 of 18 analysed vs 25 of 651 Laputta villages). The median population of 339 in selected villages was similar to 400 overall for Laputta villages.

\section{Data collection}

Consistent with guidance by Creswell, ${ }^{43}$ Foddy $^{44}$ and McNamara, ${ }^{45}$ interviews were semistructured, using an interview guide informed by the literature and non-governmental organisation (NGO) inputs that was open enough to capture additional themes ${ }^{46-48}$ and continuously refined based on interview results. Interviews with community participants (ie, service users, VHWs, midwives, village health committees (VHCs)) included (1) demographics and context, (2) service-user choices and experiences of VHWs and other providers and (3) VHW motivation, attitudes and behaviour. 
Service users were purposively sampled for diversity of age, sex and consultation reasons, among those identified from records as having visited a VHW in the previous 30 days. The proportion of service users to VHWs was over 3:1, encouraging diversity of perspectives. VHWs were purposively sampled to include one per village visited. Midwives and VHC members were opportunistically interviewed as available. Potential participants were informed about the study and given opportunities for questions and withdrawal. Oral informed consent was recorded by $\mathrm{NW}$ on a coded anonymised consent form countersigned and dated by the interpreter. Comprehensive notes of simultaneous translation were taken in English by NW, and of Burmese discussions by a non-interpreting NGO staffmember. Notes were transcribed the same day and checked with Burmese versions to address ambiguities.

Table 1 shows 54 service users, 9 CHWs, 6 AMWs, 4 midwives and 8 VHC members participated in community interviews, while 14 staff from 2 UN agencies, 7 international NGOs, and 1 national NGO participated in national interviews (ie, 1 group of 8,6 individual).

National-level key informants, recruited using expert sampling, ${ }^{49} 50$ were interviewed to provide context for community responses. First, agencies working in community programmes were invited to a group discussion. Second, those considered to have particular insight into VHW allocation were invited for individual interview. Interviews were semistructured and individuals spoke personally, not for their organisations. Comprehensive notes were taken during the group discussion. Individual interviews were audio-recorded and transcribed.

\section{Analysis}

Thematic analysis used deductive and inductive coding. ${ }^{51}{ }^{52}$ NW used Penchansky and Thomas's ${ }^{35}$ dimensionality of access framework (table 2 ) to structure deductive coding, in which access reflects interactions between service-user and provider characteristics and expectations across five dimensions (ie, availability, accessibility, acceptability, accommodation, affordability). ${ }^{36}$

This framework was chosen to provide depth and rigour to addressing the research question. However, it became clear during analysis that softer value-based themes (eg, trust, perceived quality) resonated deeply with participant experiences. Thus, NW and NH coded emergent themes inductively to refine analysis. Figure 1 provides a summary of the key components and related dimensions service users included when describing positive healthcare encounters with VHWs. Reporting followed consolidated criteria for reporting qualitative research (COREQ). ${ }^{53}$

\section{Ethics}

Work was conducted within the remit of Merlin's Memorandum of Understanding.

\section{RESULTS}

Results are presented under themes of accessibility and affordability, trust and acceptability, perceived quality and effectiveness and perceived value, disaggregated by service-user, community-provider and national perspectives and included perspectives on non-VHW providers where relevant. The 'value' of services (eg, importance to providers and service users) depended on and incorporated other themes and is therefore reported as a cross-cutting theme.

\section{Accessibility and affordability}

\section{Service users}

Accessibility in this context was reported as distance to VHWs services, waiting times and availability of needed services. Proximity of VHW services was described as most important for access. Only six of the 54 interviewed indicated their preferred provider was outside their village, with two attending more comprehensive services at the neighbouring village RHC, 5-10 min away. However, many said they wanted more services, particularly a community clinic.

It would be better if there was a clinic because there would be no need to go somewhere else. (Female service user, febrile child)

Reported waiting times for VHWs were short (eg, less than an hour) and when VHWs were unavailable, their relative or a VHC member often dispensed drugs. Several remarked that if VHW treatment was insufficient they sought private treatment, because the RHC was often closed. Availability of professional health workers, particularly midwives, was reportedly difficult.

Sometimes the midwife is travelling, so I plan to deliver with the AMW because the midwife might not be there when I need her. (Female service user, antenatal)

Participants generally reported visiting VHWs first (eg, for paracetamol) then seeking private/informal services (eg, painkilling injections from an alternative healer or 'injection man') if their health concern persisted. Several with chronic conditions sought treatment outside their village if money allowed. Service costs were not specifically captured, but have been found to vary widely. ${ }^{54}$ VHW services and drugs were officially free for service users, and were reported as free by all but one participant. This was identified as a key benefit, signalling the importance of affordability for most service users. For example, "I like the AMW because it's easily accessible drugs" (female service user, minor injury). However, some highlighted that when VHWs had no drugs, accessing healthcare became a challenge:

There's no need to pay the CHW. If the CHW has no drugs, then we have to go to the drug shop. If we have money, that's OK, if no money we don't go anywhere. (Female service user, pain/fever) 
Table 1 Summary of interviews

\begin{tabular}{|c|c|c|c|c|c|c|c|}
\hline Village code & RHC code & Population & Hard-to-reach & Service users & CHWs & AMWs & VHCs \\
\hline E & $\mathrm{P}$ & $<200$ & & 2 group & & $1 \mathrm{~F}$ & \\
\hline$P$ & $P$ & $200-400$ & & 2 & $1 \mathrm{~F}$ & $1 \mathrm{~F}$ & \\
\hline Y & $P$ & $400-600$ & & 3 & $1 \mathrm{M}$ & & \\
\hline $\mathrm{T}$ & $\mathrm{V}$ & $<200$ & & 6 group & & & \\
\hline$U$ & V & $200-400$ & & 5 group & $1 \mathrm{M}$ & & \\
\hline W & $\mathrm{V}$ & $>1000$ & & $2+3$ group & $1 \mathrm{M}$ & & \\
\hline A & $D^{\star}$ & $400-600$ & & 4 & $1 \mathrm{M}$ & $1 \mathrm{~F}$ & 1 \\
\hline 1 & $\mathrm{D}$ & $200-400$ & $\mathrm{x}$ & 3 & $1 \mathrm{M}$ & & 1 \\
\hline $\mathrm{K}$ & $F^{*}$ & $200-400$ & $\mathrm{x}$ & 3 & $1 \mathrm{~F}$ & & \\
\hline $\mathrm{F}$ & F (in village) & $>1000$ & & 3 & & $1 \mathrm{~F}$ & \\
\hline $\mathrm{H}$ & $\mathrm{F}$ & $400-600$ & & 3 & & $1 \mathrm{~F}$ & 1 \\
\hline $\mathrm{R}$ & $S$ & $200-400$ & & & No CHW & No AMW & 1 \\
\hline L & $\mathrm{J}^{*}$ & $400-600$ & & 1 & No CHW & No AMW & 1 \\
\hline$x$ & $\mathrm{~J}$ & $<150$ & $\mathrm{x}$ & 3 & & $1 \mathrm{~F}$ & \\
\hline B & Q & $800-1000$ & & 3 & $1 \mathrm{~F}$ & & \\
\hline C & Q & $400-600$ & & 3 & $1 \mathrm{M}$ & $1 \mathrm{~F}$ & 1 \\
\hline G & $Q$ & $200-400$ & $\mathrm{x}$ & 2 & & & \\
\hline M & $\mathrm{Q}^{*}$ & $200-400$ & $\mathrm{x}$ & 2 & $1 \mathrm{~F}$ & & 1 \\
\hline 0 & $\mathrm{Q}$ & $200-400$ & & 3 & & & 1 \\
\hline Total & & & 5 & $40+16$ group & $6 \mathrm{M}+4 \mathrm{~F}$ & $7 F$ & 8 \\
\hline
\end{tabular}

All interviews not marked group are individual. Two pilot interviews were excluded, making the total included 54 .

${ }^{*} \mathrm{NB}$, an additional midwife interview conducted.

AMWs, auxiliary midwives; CHWs, community health workers; F, female; M, male; RHC, Rural Health Centre; VHCs, village health committees.

Table 2 Penchansky and Thomas' dimensionality of access framework

\begin{tabular}{|c|c|}
\hline Availability & $\begin{array}{l}\text { The extent to which the provider has } \\
\text { requisite resources (eg, equipment, } \\
\text { supplies) to meet service-user needs }\end{array}$ \\
\hline Accessibility & $\begin{array}{l}\text { Geographic accessibility is determined } \\
\text { by how easily service users can } \\
\text { physically reach the provider's location }\end{array}$ \\
\hline Acceptability & $\begin{array}{l}\text { The extent to which service users and } \\
\text { providers are comfortable with each } \\
\text { other's immutable characteristics (eg, } \\
\text { sex, age, status) }\end{array}$ \\
\hline Affordability & $\begin{array}{l}\text { The extent to which the provider's } \\
\text { charges relate to service user's ability } \\
\text { and willingness to pay }\end{array}$ \\
\hline Accommodation & $\begin{array}{l}\text { The extent to which the provider's } \\
\text { services are organised to meet service } \\
\text { user's constraints and preferences (eg, } \\
\text { opening times, communications, } \\
\text { appointments) }\end{array}$ \\
\hline
\end{tabular}

The previous quote also highlights the importance of affordability as it implies that money is not always available for drugs, and when that is the case, as the female service user suggested "we don't go anywhere".

However, some VHWs charged for certain services (eg, childbirth). Anticipated costs (eg, fear of hospital fees) influenced some to avoid referral for obstetric complications. An existing relationship was sometimes relied on when money was insufficient: "He [injection man] knows us and will help us even if we don't have money" (male service user). Charges for midwife-attended delivery were reported as varying significantly between villages, with traditional birth attendant (TBA) or AMW charges lower, or in one case "No money, just some gifts" (female service user, antenatal).

\section{Community providers}

Most VHWs (10/15) were routinely visited by small number of service users from other villages or temporarily resident between villages. Estimated travel times for visiting service users were $10 \mathrm{~min}$ to an hour on foot, or in one case, $30 \mathrm{~min}$ by motorboat. Most VHWs said they would accept visiting service users, but would not travel to them. However, one-third (ie, three men, three women) provided services in other villages, travelling $10 \mathrm{~min}$ to an hour on foot or by boat. VHCs reportedly did not cooperate between villages to organise health services, at most coordinating immunisation visits or sharing information at RHC meetings.

Affordability of non-voluntary services was acknowledged as a concern by VHWs and midwives. Four VHWs noted that they were mainly used by poor people and some VHCs described the pro-poor impact they felt they were having.

VHWs could be more flexible, as their service users were their neighbours. However, this meant they could be expected to be available at any time.

The community thinks the volunteers have responsibility to support them full time. (Male CHW). 


\begin{tabular}{|l|}
\hline Availability of staff and \\
drugs and affordability \\
(related to availability, \\
accessibility, affordability) \\
Proximity of services \\
Waiting times \\
Availability of drugs \\
Availability of VHW \\
Affordability of the services \\
and medication \\
\hline
\end{tabular}

Quality of healthcare and effectiveness (related particularly

to acceptability, accommodation) Skills of the VHWs

Responsiveness to service users' needs

Adequate provision of information Quality of medication

Appropriateness and quality of treatment

Trusting relationships based on
experience of the VHWs (related
particularly to acceptability,
accommodation)
Personal relationship developed
over time
Sources of trust: own experience
and experience of other patients

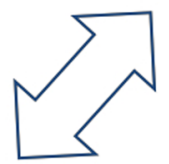

Figure 1 Key components and related dimensions for a positive healthcare encounter with village health workers (VHWs) as reported by service users (text in brackets highlights relevant dimensions of access from table 2).

\section{National perspectives}

Distance from a health facility was reported as the preferred VHW allocation criterion, with participants noting as unlikely that people would travel far or incur costs to give or receive services. Several emphasised the degree of unmet need in Myanmar, with interventions such as peer-counselling requiring enough VHWs to enable adequate one-to-one contact. None suggested that a CHW and AMW were necessary or sustainable in each community.

\section{Trust and acceptability}

\section{Service users}

Whereas proximity, affordability, availability of drugs and VHW services were reported as crucial components in service-user decisions to access healthcare, trust in providers also emerged as a salient and recurrent theme. Service users reported being more willing to travel long distances to access providers they could trust.

Several participants articulated the importance of trust, particularly when VHWs were not their first choice. The most extreme example was a woman's 2.5-hour boat journey to the 'injection man' (ie, informal provider) in her mother's village whenever she was ill, because he was trustworthy and familiar.

We trust [that] midwife [...] because [the other] one only has 3 years' experience. (Female service user, antenatal)

The volunteer knows about the diseases well. He can give accurate treatment. (Male service user, 'sneezing')

Perceived provider experience and personal relationships developed over time were reported as the two key dimensions of a trusting encounter between a service user and provider. In this context, trusting relationships developed when one or both dimensions were present.
For example, several participants made reference to familiarity and provider experience:

I'm also familiar with that CHW. He has more experience. (Female service user, malnutrition)

Conversely, not having enough experience was sufficient basis to distrust a provider. For example:

The AMW's house is far away, she has no experience and can't deliver... No trust. (Female service user, child fever)

Most, when describing trusting relationships, referred to providers 'knowing them well' as a precursor to trusting their advice. For example, the following service user knew his provider and reported trusting him, which he considered more important than the distance required to reach him.

It's a long way to go. I go every time I'm ill, he knows me well and I trust him. (Male service user, sneezing)

Finally, participants reported relying on their own and other service users' experience when deciding to trust a provider or medication. For example, a woman who bought medication from a drug seller explained:

At the hospital, some doctors give this to some cancer patients... The patients who take it said it was good so I am taking it myself. (Female service user, breast tumour)

\section{Community providers}

Trust was mentioned by five VHWs. For most, trust indicated VHWs were working effectively and suggested that when service users trusted them, their advice was followed. For example:

I get trust from the villagers. They take advice from me. (Female provider, AMW) 
Some VHWs mentioned being visited by service users from other villages, even if they were not the closest option or there was a VHW in that village. Provider choice seemed linked to trust and familiarity.

\section{National perspectives}

Participants were familiar with the themes of trust and acceptability, particularly regarding ongoing demand for TBAs who were perceived to offer additional support and benefits during childbirth that AMWs and midwives did not provide, for example, cooking, cleaning, nonmedical care.

\section{Perceived quality and effectiveness \\ Service users}

Quality of care was reported and linked to the perceived experience and skills of providers and the effectiveness of drugs provided. Compared with other providers, VHWs were perceived as only able to treat minor illnesses and injuries and it was suggested that other providers were needed for more serious conditions:

Having a volunteer is more effective [than not having one], but she can treat only minor injuries.

Some participants perceived differences between the essential drugs available from VHWs and those in drug shops.

Not for me, the CHW drugs don't relieve my pain. (Female service user, child health, going elsewhere for her own chest pain)

An advantage mentioned of VHWs was their capacity to accommodate service-user needs and choices, as they resided locally and could be approached at any time. The next quotes highlight VHW responsiveness, which was perceived as a key component of good quality healthcare:

Don't need to wait-even if I go after midnight, he's very flexible. (Female service user, 'indigestion')

He's easily accessible, we can go any time. (Wife of 'sneezing' service user)

A common theme that emerged throughout the interviews was the perception that to get good quality treatment, 'injections' were needed rather than oral medication:

I went to [informal provider] because the AMW can't give injections... (Female service user, oral contraceptive pill (OCP))

\section{Community providers}

VHW views on potentially increasing their workload were divided, some saying they could do more and others that they were already too busy. Nevertheless, no correlation was found between VHW assertions of being busy and their overall effectiveness in terms of either population covered or consultation rates in service records. However, all VHWs also had paid or family commitments requiring their time and attention. Five of the nine female VHWs reported their other activities as unremunerated household or social commitments, while remaining VHWs, that is, all men and the other four women, were employed.

Efficiency and competition were concerns, if either too few or too many VHWs were allocated. One AMW, who had delivered nine babies in the 20 months since training, noted "Some friends are afraid to deliver because they've had no practice." Two midwives mentioned possible competition between AMWs and midwives. Five villages had, or aimed to have, at least two VHWs, because of size or remoteness. In one, the male CHW helped the AMW because as a young woman she was unable to conduct visits at night. One midwife wanted an additional volunteer as a way of compensating for a poorly functioning VHW, while another suggested that AMWs needed to do more. One midwife said VHWs would be more effective if they were paid.

\section{National perspectives}

Balancing service-user access with appropriate service quality generated much discussion, especially regarding dispensing medicines. Participants were divided on whether the benefits outweighed the risks, or whether VHWs should concentrate solely on health promotion even if this was not what service users wanted. Two noted that providing something tangible (eg, drugs, supplies) increased service usage and motivated VHWs. Most indicated that volunteers-particularly AMWsshould not be posted in villages with a health facility. Participants noted potential risks of VHWs providing more than they were authorised to.

\section{Value of the services provided by VHWs \\ Service users}

Service users emphasised the benefits of accessing drugs easily and treating minor illnesses and injuries locally.

I always take OCP from the AMW [...] now I don't have to buy. (Female service user, OCP)

Most said they appreciated the work of VHWs, though many mentioned they would like additional or different services. Two mentioned VHWs facilitating immunisation, and several discussed interactions with VHWs related to health education. VHWs were encouraged to provide health promotion. While $24 \%(13 / 54)$ of service users listed preventive actions they had learnt (eg, keeping themselves and environment clean, being careful with food), those who attended health education sessions often could not remember what they were about. Approximately 25\% mentioned the value of VHW referral to other services. 
My child was vomiting [...] and the AMW referred to [RHC] because she said [...] that when the child is vomiting to go to the RHC. (Female service user, vomiting child)

\section{Community providers}

VHWs described the value they provided.

Before I was CHW, some mothers were afraid to get immunisation for children because children can get fever from immunisation therefore they were afraid. But after I provided information, [...] now all children get immunised. (Male provider, CHW)

Referral was frequently mentioned as a useful VHW contribution, with midwives emphasising that VHWs were a link between villages and basic health staff, NGOs or Department of Health. Midwives valued VHWs' community knowledge, and said AMWs particularly saved them time: 'I'm not effective if the volunteers are not there.' In some cases, AMW and CHW duties appeared to overlap (eg, AMWs treating adult illnesses, CHWs giving antenatal supplements and Clean Delivery Kits, and maintaining lists of pregnant women), although this was encouraged only with specific dual training. One midwife suggested: "The AMW can be dual function because all activities of the AMW and CHW are primary care. It's not an overload."

Community providers reported other benefits, besides the expected intrinsic value of providing healthcare, including feelings of self-worth, pride, and being able to use skills learnt to protect their families.

Every time I wear the uniform I feel proud. (Female provider, AMW)

\section{National perspectives}

While valuing VHWs' local knowledge and connections, some participants questioned cost-effectiveness and productivity. Views varied on the value of VHWs' educational role, with two saying group health education sessions had yet to be proven successful while four saw a role for individual education (eg, peer-counselling). One noted that some areas had too many VHWs from different organisations. All agreed there was a long-term role for VHWs in supporting wider health and social services. Greater coordination of VHWs was recommended to avoid duplication and provide greater flexibility across cadres. Participants identified three areas for further efforts: (1) training content and methods, (2) motivation and incentives and (3) supporting midwives to supervise effectively.

\section{DISCUSSION}

\section{Primary findings}

Results indicated that service users valued VHW services, particularly for simple issues, because they were nearby and usually free. However, if they decided VHW service quality was insufficient or health issues too complex (eg, chronic conditions, childbirth) they sought healthcare elsewhere, usually at greater cost. Additionally, injection 'treatments' (eg, usually vitamins or glucose) were considered particularly effective and because VHWs rightly did not provide these, demand for informal services continued. This study is the first, to authors' knowledge, documenting provider and service-user perceptions of VHW service provision in Myanmar. Understanding service-user perspectives of services at community and other levels is a critical aspect of achieving the quality and consumer satisfaction aspects of government strategic plans to ensure universal health coverage. ${ }^{55} 56$

Accessibility, in terms of distance to a VHW, and availability, in terms of VHW numbers, were clearly important. Service users were unlikely to travel outside their village just for the essential drugs a VHW could distribute, unless there was an existing relationship with that VHW or no alternative. While distance to a health facility was emphasised by national participants and the literature as an important determinant, ${ }^{57-60}$ many service users reported avoiding health facilities because of perceived lack of staff, reinforcing the finding that a more nuanced, patient-centred approach would improve health services design.

Service users valued VHWs for providing free, local, frontline services, while recognising the limitations of the relatively basic services VHWs offered ${ }^{59}$ Trust and acceptability were closely related to familiarity, and also to perceived quality and service effectiveness. Quality of care was also related to the perceived experience and skills of providers and the effectiveness of the drugs being administered. These were complex issues, as service users were willing to overcome barriers if they trusted a particular provider or expected a desired service.

Findings indicate that trust is a multilayered concept. ${ }^{40-42}$ Calnan and Rowe suggest that trust has two main characteristics, a rational component based on judgments and beliefs and an emotional component based on affective relationships. ${ }^{61}$ Academics have distinguished between interpersonal trust, based on the relationship between two individuals (eg, service user and provider), and institutional trust, relating to perceptions or experiences of health institutions and systems. ${ }^{40}{ }^{41} 61-66$ Those studying trust in healthcare settings have suggested the possible positive influences of trusting relationships, including influence on health outcomes by improving service-user satisfaction, potential links to treatment adherence, predicting continuity and facilitating information disclosure. ${ }^{616667}$ The type of trust reported by participants in this study related to interpersonal trust, which may be more influenced by the emotional component Calnan and Rowe described. Results emphasise the importance of trust between service users and VHWs. In some cases, service users were willing to travel long distances for providers they trusted and VHWs emphasised that service users were more willing to follow their advice when they trusted 
them. However, further exploration of trust is necessary in this context.

\section{Policy implications}

Given government aims to move towards universal health coverage and SDG achievement, it is paramount to identify how community-based services can be scaled up cost-effectively to provide equitable access. As Risso-Gill et $a l^{68}$ noted, despite some areas being supported by international agencies, overall community services require additional resources to provide effective care. VHWs will likely remain important. While focusing on accessibility and availability would be most straightforward for MoHS and international partners, community responses indicated that other aspects sometimes overrode these criteria. ${ }^{69-73}$

Accessing free local services was valued. Volunteers need sufficient experience, large enough catchments to ensure regular application of their skills, health system support (eg, to refer appropriately), and the skills to build trusting relationships. Evidence supports participant views that the ability to dispense at least some medicines was necessary in establishing VHWs' status. ${ }^{12}$ However, there are valid concerns about others distributing drugs in VHWs' absence and wide availability of antibiotics in shops even in small villages. One compensatory approach, training drug-sellers (eg, to provide malaria diagnosis and treatment), has been tested in several countries though not formally in Myanmar at the time of writing. ${ }^{74}$

An important consideration for policymakers, when deciding how best to scale up services, is that VHWs are frontline providers for most vertical programmes (eg, malaria, tuberculosis, primary healthcare) and required to complete activities and provide detailed records for many government and partner programmes. The extra workload imposed by these demands can become significant, particularly given the voluntary status of VHWs and their existing work and family commitments. More in-depth consultation between key stakeholders, for example, MoHS, township medical officers, VHCs, donors and NGOs supporting community-based programmes, could strengthen coordination and minimise duplication. It would also help strengthen the evidence base around ensuring maximum effectiveness, for example, responsible access to medicines.

When developing human resources plans, results suggest that planners should consider softer values embedded within health systems. Service-user perceptions of trust and quality healthcare are important considerations in planning and implementing effective health services.

\section{Limitations}

While social acceptability bias may have affected some answers, particularly at community level, ${ }^{75}$ the range of participants helped counteract this. Research was not designed to identify relationships between demographic factors and decision-making, which may warrant follow-up. Despite limitations, results offer a basis for further investigation to plan for the future, and inform wider discussion about access to VHW services, particularly in relation to any future scale-up of volunteer cadres nationally.

\section{CONCLUSIONS}

Results show that VHWs continue to be a relevant part of health system responses to needs in Myanmar, but there are complex issues in ensuring efficient and effective provision. Further research into trust-building, developing quality perceptions and resulting service-user choices would help ensure effective and acceptable provision while balancing equity of access.

Acknowledgements Authors thank interviewees for their openness and Department of Health staff in Laputta for support. Thanks to Merlin staff, particularly in Laputta for supporting research implementation, including shortlisting villages, critiquing and translating tools, logistics and discussing cultural relevance and findings. Authors acknowledge Gill Walt (LSHTM) for discussing initial planning, Chris Grundy (LSHTM) for GIS advice and Egbert Sondorp (Royal Tropical Institute Amsterdam) and Ruairi Brugha (Trinity College Dublin) for informing the literature search.

Contributors NW developed the study, conducted data collection and analysis and drafted the manuscript. AY conducted initial modelling, addressed database queries and critically reviewed the manuscript. PS conceptualised the study and critically reviewed the manuscript. FC contributed to study conceptualisation and interview guide development and critically reviewed the manuscript. HL-Q contributed to data interpretation and critically reviewed the manuscript. NH contributed to study design, data analysis and interpretation, and critically revised the manuscript. All authors approved the version for submission.

Funding Travel costs were supported by the Chadwick Trust and Old Waconians' Association but no research funding was obtained.

\section{Competing interests None declared.}

Ethics approval London School of Hygiene \& Tropical Medicine Research Ethics Committee (Reference 011/119)

Provenance and peer review Not commissioned; externally peer reviewed.

Data sharing statement No additional data are available.

Open Access This is an Open Access article distributed in accordance with the Creative Commons Attribution Non Commercial (CC BY-NC 4.0) license, which permits others to distribute, remix, adapt, build upon this work noncommercially, and license their derivative works on different terms, provided the original work is properly cited and the use is non-commercial. See: http:// creativecommons.org/licenses/by-nc/4.0/

\section{REFERENCES}

1. Walt G. Community Health Workers: just another pair of hands. Milton Keynes: Open University Press, 1990.

2. Abbatt F. Scaling up health and education workers: community health workers. London: DFID Health Systems Resource Centre, 2005.

3. Bhutta ZA, Chopra M, Axelson H, et al. Countdown to 2015 decade report (2000-10): taking stock of maternal, newborn, and child survival. Lancet 2010;375:2032-44.

4. Campbell C, Scott K. Retreat from Alma Ata? The WHO's report on Task Shifting to community health workers for AIDS care in poor countries. Global Public Health 2011;6:125-38.

5. Haines A, Sanders D, Lehmann U, et al. Achieving child survival goals: potential contribution of community health workers. Lancet 2007;369:2121-31. 
6. Hall JJ, Taylor R. Health for all beyond 2000: the demise, of the Alma-Ata declaration and primary health care in developing countries. Med J Aust 2003;178:17-20.

7. Liu A, Sullivan S, Khan M, et al. Community health workers in global health: scale and scalability. Mt Sinai J Med 2011;78:419-35.

8. World Bank. World Development Report 1993 Investing in Health. New York, 1993

9. WHO. The world health report 2008. Primary health care-Now more than ever. Geneva: World Health Organization, 2008.

10. Lewin S, Munabi-Babigumira S, Glenton C, et al. Lay health workers in primary and community health care for maternal and child health and the management of infectious diseases. Cochrane Db Syst Rev 2010;(3):CD004015.

11. Rosenthal EL, de Heer $\mathrm{H}$, Rush $\mathrm{CH}$, et al. Focus on the future: a community health worker research agenda by and for the field. Prog Community Health Partnersh 2008;2:183-4, 225-35.

12. Lehmann U, Sanders D. Community health workers: what do we know about them? The state of the evidence on programmes, activities, costs and impact on health outcomes of using community health workers. Geneva: World Health Organization, 2007.

13. Crigler L, Hill K. Rapid assessment of community health worker programs in USAID priority MCH countries. Draft Tool for field testing. Bethesda: USAID Health Care Improvement Project, 2009.

14. Global Fund to fight AIDS Tuberculosis and Malaria. Community systems strengthening framework. Geneva: The Global Fund to fight AIDS Tuberculosis and Malaria, 2011.

15. WHO. Task shifting: rational redistribution of tasks among health workforce teams: global recommendations and guidelines. Geneva: World Health Organization, 2008.

16. Perry HB, Dhillon RS, Liu A, et al. Community health worker programmes after the 2013-2016 Ebola outbreak. Bull World Health Organ 2016;94:551-3

17. Perry HB, Zulliger R, Rogers MM. Community Health Workers in Low-, Middle-, and High-Income Countries: An Overview of Their History, Recent Evolution, and Current Effectiveness. Ann Rev Public Health 2014;35:399-421.

18. WHO. Estimating the cost of scaling-up maternal and newborn health interventions to reach universal coverage: methodology and assumptions. Geneva: World Health Organization, 2005.

19. Dahn B, Woldemariam A, Perry H, et al. Strengthening primary health care through community health workers: investment case and financing recommendations. Geneva: Office of UN Secretary General's Special Envoy for Financing the Health Millennium Development Goals and for Malaria, 2015

20. Balabanova D, Mckee M, Mills A, eds. 'Good health at low cost' 25 years on: what makes a successful health system? London: London School of Hygiene and Tropical Medicine, 2011.

21. Haken N, Messner J, Hendry K, et al. The Fragile States Index 2014. Washington DC: The Fund for Peace, 2014. http://library fundforpeace.org/library/cfsir1423-fragilestatesindex2014-06d.pdf

22. UNDP. Human Development Report 2014. 2014.

23. Victora CG, Bahl R, Barros AJ, et al. Breastfeeding in the 21st century: epidemiology, mechanisms, and lifelong effect. Lancet 2016;387:475-90.

24. mdgTrack. Monitoring progress towards the Millennium Development Goals, 2011-2015. Myanmar: TAC Economics, 2015.

25. Sein TT, Myint P, Tin N, et al. The Republic of the Union of Myanmar Health System Review. Asia Pacific Observatory on Public Health Systems and Policies, 2014.

26. WHO Global Health Observatory. Official Development Assistance (ODA) for health to Myanmar. ODA recipient country profiles, 20002010. World Health Organization, 2015

27. Dept of Planning. Myanmar Multiple Indicator Cluster Survey 20092010: monitoring the situation of children and women. Yangon: Ministry of National Planning and Economic Development, Ministry of Health, UNICEF, 2011.

28. MoH. Health in Myanmar. Myanmar, 2010.

29. WHO Country Office for Myanmar. WHO country cooperation strategy 2008-2011. Yangon, Myanmar: World Health Organization, 2008.

30. MoH. Revitalizing primary health care country experience: Myanmar Regional Conference on Revitalizing Primary Health Care. Jakarta: SEARO, 2008.

31. $\mathrm{MOH}$. AMW and CHW mobilization. Auxiliary Midwife (AMW) \& Community Health Worker (CHW) Mobilization Meeting. Naypyitaw: Ministry of Health, 2014.

32. Low S, Tun KT, Mhote NP, et al. Human resources for health: task shifting to promote basic health service delivery among internally displaced people in ethnic health program service areas in eastern Burma/Myanmar. Glob Health Action 2014;7:24937

33. WHO. WHO global strategy on people-centred and integrated health services: interim report. Geneva: World Health Organization, 2015.
34. Partners in Health. Improving outcomes with community health workers. Boston, MA: Programme Management Guide, 2011.

35. Penchansky R, Thomas JW. The concept of access: definition and relationship to consumer satisfaction. Med Care 1981;19:127-40.

36. McLaughlin CG, Wyszewianski L. Access to care: remembering old lessons. Health Serv Res 2002;37:1441-3.

37. Farzadfar F, Murray CJL, Gakidou E, et al. Effectiveness of diabetes and hypertension management by rural primary health-care workers (Behvarz workers) in Iran: a nationally representative observational study. Lancet 2012;379:47-54.

38. Prasad BM, Muraleedharan VR. Community Health Workers: a review of concepts, practice and policy concerns. London: International Consortium for Research on Equitable Health Systems, 2007.

39. Howard N, Campbell F, Watt N, et al. A rational-planning approach to village health worker placement for strengthening community-based provision in Myanmar: an operational study. Cape Town: Third Global Symposium on Health Systems Research, 2014.

40. Topp SM, Chipukuma JM. A qualitative study of the role of workplace and interpersonal trust in shaping service quality and responsiveness in Zambian primary health centres. Health Policy Plan 2016;31:192-204.

41. Singh D, Cumming R, Negin J. Acceptability and trust of community health workers offering maternal and newborn health education in rural Uganda. Health Educ Res 2015;30:947-58.

42. Gilson L. Trust in health care: theoretical perspectives and research needs. J Health Organ Manag 2006;20:359-75.

43. Creswell JW. A framework for design. Research design: qualitative, quantitative, and mixed methods approaches. 2nd edn. Thousand Oaks, CA: Sage, 2003.

44. Foddy W. Constructing questions for interviews and questionnaires: theory and practice in social research. Cambridge: Cambridge University Press, 1994.

45. McNamara C. General guidelines for conducting interviews. Secondary General guidelines for conducting interviews. 2009. http:// managementhelp.org/businessresearch/interviews. htm\#anchor615874

46. Gall MD, Gall JP, Borg WR. Educational research: an introduction. 7th edn. Boston, MA: A \& B Publications, 2003.

47. Patton MQ. Qualitative interviewing. Qualitative evaluation and research methods. 2nd edn. Newbury Park, CA: Sage, 1990.

48. Turner DW III. Qualitative interview design: a practical guide for novice investigators. Q Rep 2010;15:754-60.

49. Palys T. Purposive sampling. In: Given LM, ed. The Sage encyclopedia of qualitative research methods. Thousand Oaks, CA: Sage, 2008:697-8.

50. Maxwell JA. Methods: what will you actually do? Qualitative research design: an interactive approach. 2nd edn. Thousand Oaks: Sage, 2005.

51. Taylor C, Gibbs GR. How and what to code. Secondary how and what to code 19th Feb 2010. 2010. http://onlineqda.hud.ac.uk/Intro_ QDA/how_what_to_code.php

52. Saldana JM. An introduction to codes and coding. The coding manual for qualitative researchers. Thousand Oaks, CA: Sage, 2009.

53. Tong A, Sainsbury P, Craig J. Consolidated criteria for reporting qualitative research (COREQ): a 32-item checklist for interviews and focus groups. Int J Qual Health Care 2007;19:349-57.

54. Khaing IK, Malik A, Oo M, et al. Health care expenditure of households in Magway, Myanmar. Nagoya J Med Sci 2015;77:203-12.

55. MoHS. Strategic directions for universal health coverage Myanmar. Naypyidaw: Ministry of Health and Sport, 2014.

56. WHO. What are the challenges facing Myanmar in progressing towards Universal Health Coverage? Myanmar Health Systems in Transition Policy Notes Series. Asia Pacific Observatory on Health Systems and Policies, 2015.

57. Rutherford ME, Mulholland K, Hill PC. How access to health care relates to under-five mortality in sub-Saharan Africa: systematic review. Trop Med Int Health 2010;15:508-19.

58. Thaddeus S, Maine D. Too far to walk-maternal mortality in context. Soc Sci Med 1994;38:1091-110.

59. Thandar MM, Kyaw MP, Jimba M, et al. Caregivers treatment-seeking behaviour for children under age five in malaria-endemic areas of rural Myanmar: a cross-sectional study. Malar J 2015;14:1.

60. Chamroonsawasdi K, Soe M, Charupoonphol P, et al. Rate of utilization of skilled birth attendant and the influencing factors in an urban Myanmar population. Asia Pac J Public Health 2015;27:521-30.

61. Calnan M, Rowe R. Trust relations in a changing health service. $J$ Health Serv Res Policy 2008;13(Suppl 3):97-103. 
62. Mechanic D. Public trust and initiatives for new health care partnerships. Milbank Q 1998;76:281-302.

63. Luhmann N. Familiarity, confidence, trust: problems and alternatives. In: Gambetta D, ed. Trust making and breaking cooperative relations. Oxford: Basil Blackwell Ltd, 1998.

64. Goold S, Klipp G. Managed care members talk about trust. Soc Sci Med 2002:54:879-88.

65. Hall MA, Zheng B, Dugan E, et al. Measuring patients' trust in their primary care providers. Med Care Res Rev 2002;59:293-318.

66. Calnan M, Rowe R. Trust matters in health care. Maidenhead: Open University Press, 2008.

67. Thom D, Hall MA, Pawlson L. Measuring patients' trust in their physicians when assessing quality of care. Health Aff (Millwood) 2004;23:124-32.

68. Risso-Gill I, McKee M, Coker R, et al. Health system strengthening in Myanmar during political reforms: perspectives from international agencies. Health Policy Plan 2014;29:466-74.

69. Dreesch N, Dolea C, Dal Poz MR, et al. An approach to estimating human resource requirements to achieve the Millennium Development Goals. Health Policy Plan 2005;20:267-76.
70. 3MDG Fund. Description of Action-Multi-donor 3MDG fund 201216. Yangon, 2012

71. Kurowski C, Wyss K, Abdulla $\mathrm{S}$, et al. Human resources for health: requirements and availability in the context of scaling-up priority interventions in low-income countries. Case studies from Tanzania and Chad. London: Department for International Development, 2003.

72. Mukanga D, Tibenderana JK, Peterson S, et al. Access, acceptability and utilization of community health workers using diagnostics for case management of fever in Ugandan children: a cross-sectional study. Malaria J 2012;11:121.

73. Shengelia B, Tandon A, Adams OB, et al. Access, utilization, quality, and effective coverage: an integrated conceptual framework and measurement strategy. Soc Sci Med 2005;61:97-109.

74. Awor $\mathrm{P}$, Wamani $\mathrm{H}$, Bwire $\mathrm{G}$, et al. Private sector drug shops in integrated community case management of malaria, pneumonia, and diarrhea in children in Uganda. Am J Trop Med Hyg 2012;87:92-6.

75. Paulhus DL. Measurement and control of response bias. In: Robinson JP, Shaver PR, Wrightsman LS, eds. Measures of personality and social psychological attitudes. New York: Academic Press, 1991:17-59. 